\title{
The IMA - looking into the future
}

DOI: http://dx.doi.org/10.5915/22-4-14311

The Islamic Medical Association (IMA) has come a long way since a handful of dedicated muslims met under the shadow of "Muslim Students Association" in 1967. Credit belongs to Dr. Mubin Akhter, our first president, and his entourage that laid the foundation of what we see today as IMA. Yes, we have come a long way, "al-hamdulillah" — but we have a longer way to go. We have only about $15 \%$ of an estimated 10,000 U.S. Muslim physicians in our fold so far and we need to do a lot more to be responsive to the needs of the Muslim health professionals in this country. For us to survive and flourish into the next century we have to expand our membership base. Let us all rededicate ourselves to this fundamental need of ours that is essential for our existance. In this context it is of paramount importance to involve the health care professionals and researchers of tomorrow - Muslim medical students and housestaff that, "in-shā' Allāh", will be the back bone of the future IMA. As first generation immigrants we tend to feel very strong about our ethnic background but this is not the case with our children. They can be bound basically only by one force - the force of Islam and in that context it is more important to introduce IMA to them. It is hoped that you will all assist us in collecting all the data we can about this important segment of ours.

The Journal of Islamic Medical Association (JIMA), "al-hamdulillāh", has come a long way as well since its inception. It has been upgraded constantly to its present form where you see editorials, original research work, review articles, case reports etc. included regularly in the Journal. It is a tribute to the untiring efforts of our editors and reviewers, along with the authors, who have put in long hours to assure the timely publication of JIMA. We do, however, have another hurdle ahead of us - that is the inclusion of JIMA in the Cumulative Index Medicus - currently the primary goal of the Editorial Board and the well-wishers of JIMA. Obviously this will not be possible without the contribution of a large number of our members (and nonmembers) who have achieved a high status in the academic and research fileds.

JIMA is an unique publication in its contents with articles of current medical interest soaked with
Islamic perspectives, present day scientific advances as they relate to "Fiqh", Islam and medical ethics, and, of course, the on-going medical research and updates. It brings the Muslim medical scholars on a platform wherefrom they can address their brethern around the globe and share with them their interests, experience and research work. It also provides our authors an exposure into the upper echelons of the Muslim medical scholars. Of late the circulation of JIMA has improved and is being sent to medical schools and university hospitals around the Muslim world and periodically we have received gratifying letters from them about JIMA. This has also led to articles and publications originating from different parts of the Muslim world which is a big achievement in itself.

The regularity of publication of JIMA is not a small achievement either, considering that the editors do not have special staff at their disposal and have to interact with the authors and the reviewers who have done an outstanding job in reviewing the articles in a very timely fashion. The Journal, however, is still handicapped because of insufficient publication of original articles and research work which led to denial of its inclusion in the Index Medicus last year. The Executive Board, the editors, and the reviewers are more than willing to go the extra mile they have to in order to put the best product out, but to do so they will need the ingredients - to make it the best. They do need as much of your publishable work as possible to further upgrade the quality of the Journal to achieve a level where it will be accepted for inclusion in Index Medicus. I would, therefore, plead with our academicians, practitioners and researchers alike to make it a personal crusade to bring the Journal to that level so that every hospital in the country will subscribe to it without hesitation. Academicians and researchers have an unique opportunity to contribute to the growth of IMA in this regard and I know we all will be proud when JIMA is indexed. I can only hope that it is sooner than later.

Was-Salām

Khalid J. Qazi, M.D., F.A.C.P. President, IMA 6343 Transit Road Depew, NY 14043-1092 